\title{
Seroprevalence of Hydatidosis in Referrers to Laboratories of Khoda Afarin Health Center in East Azarbaijan, Iran, within 2018 to 2019
}

\author{
Mohammad Fallah ${ }^{1}$, Afshin Azimi², Seyed Mousa Motavalli Haghi ${ }^{3}$, Nazila Sarafraz ${ }^{4}$, \\ Mahdi Parsaei ${ }^{2,5}$,*iD, Mahdi Hassanzadeh ${ }^{6}$, Saber Alizadeh ${ }^{6}$, Ahad Shahnami ${ }^{6}$, Ali \\ Nayebi $^{7}$
}

${ }^{1}$ Professor, Department of Medical Parasitology and Mycology, School of Medicine, Hamadan University of Medical Sciences, Hamadan, Iran

2 PhD Student of Parasitology, School of Medicine, Hamadan University of Medical Sciences, Hamadan, Iran

3 Parasitologist, School of Medicine, Hamadan University of Medical Sciences, Hamadan, Iran

${ }^{4}$ PhD Student of Parasitology, School of Medicine, Zanjan University of Medical Sciences, Zanjan, Iran

${ }^{5}$ PhD Student of Parasitology, Student Research Committee, Hamadan University of Medical Sciences, Hamadan, Iran

${ }^{6}$ Vicechancellor of Health Deputy, Tabriz University of Medical Sciences, Tabriz, Iran

${ }^{7}$ Healthcare Network of Khoda Afarin County, Tabriz University of Medical Sciences, Tabriz, Iran

* Corresponding Author: Mahdi Parsaei, Student Research Committee, Hamadan University of Medical Sciences, Hamadan, Iran.Email: m.parsaei@edu.umsha.ac.ir

Received: 28.10 .2019

Accepted: 22.01 .2020

How to Cite this Article: Fallah M, Azimi A, Motavalli Haghi SM, Sarafraz N, Parsaei M, Hassanzadeh M, Alizadeh S, Shahnami A, Nayebi A. Seroprevalence of Hydatidosis in Referrers to Laboratories of Khoda Afarin Health Center in East Azarbaijan, Iran, within 2018 to 2019. Avicenna J Clin Med. 2020; 26(4): 234-240. DOI: $10.29252 / \mathrm{ajcm} .26 .4 .234$

\section{Abstract}

Background and Objective: Infection with hydatid cysts or hydatidosis, which is a zoonotic disease, is caused by the larval stage of Echinococcus granulosus in humans and animals. Hydatidosis infection is endemic in most parts of the country. In Khoda Afarin County in East Azarbaijan, Iran, as a center of animal husbandry, there is a possibility of high exposure to the Echinococcus granulosus egg. This study was carried out to determine the seroprevalence of hydatidosis in this county population.

Materials and Methods: In this descriptive cross-sectional study, 295 blood samples were collected from the population of Khoda Afarin County in a test tube without anticoagulant within 2018 to 2019. The samples were evaluated using enzyme-linked immunosorbent assay to measure immunoglobulin $\mathrm{G}$ against Echinococcus granulosus. The demographic data of the participants were gathered by a questionnaire, and the results were analyzed using SPSS software (version 18).

Results: Out of 295 samples, 12 (4.07\%) people were positive. The highest percentage of seropositivity was reported in the age group of 30-39 years with $3(3.53 \%)$ cases. The frequency rates of seropositivity in urban and rural subjects were $16.7 \%$ and $83.3 \%$, respectively.

Conclusion: The obtained results showed a significant prevalence of infection in the study population (similar to those reported in some other studies carried out in different parts of Iran). Therefore, it is essential to focus on the control and prevention of the disease as a priority disease in Khoda Afarin County among different occupations and age groups.

Keywords: Echinococcus granulosus, Hydatidosis, Seroprevalence 


\title{
شيوع سر مى هيداتيدوز در مر اجعه كنند تان به آزمايشَاههاى مركز بهداشت شهر ستان خدا آفرين در استان آذربايجان شرقى طى سالهاى
}

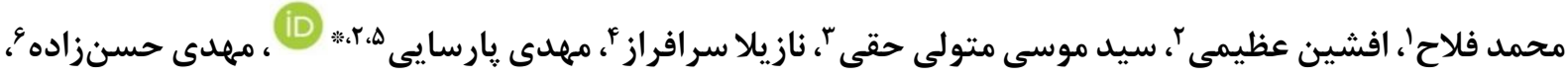

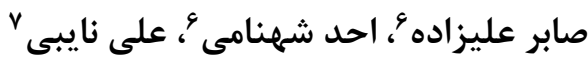

' استاد، گروه انكل شناسى و قارجشناسى، دانشكده يزشكى، دانشعاه علوم يزشكى همدان، همدان، ايران

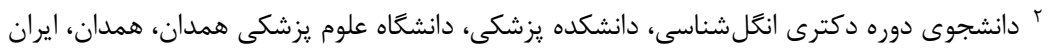

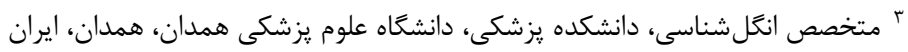

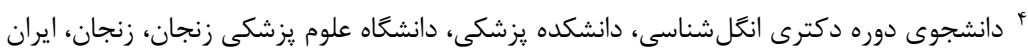

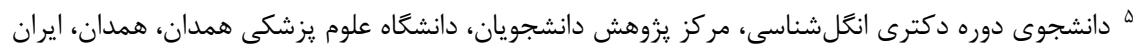

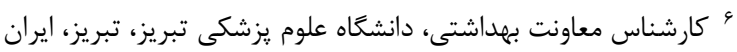

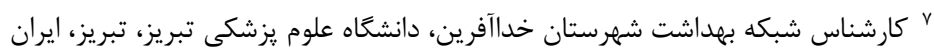

m.parsaei@edu.umsha.ac.ir : نويسنده مسئول: مهدى يارسايى، مركز يزوهش دانشجويان، دانشاه علوم يزشكى همدان، همدان، ايران. ايميل

\begin{tabular}{|c|c|}
\hline 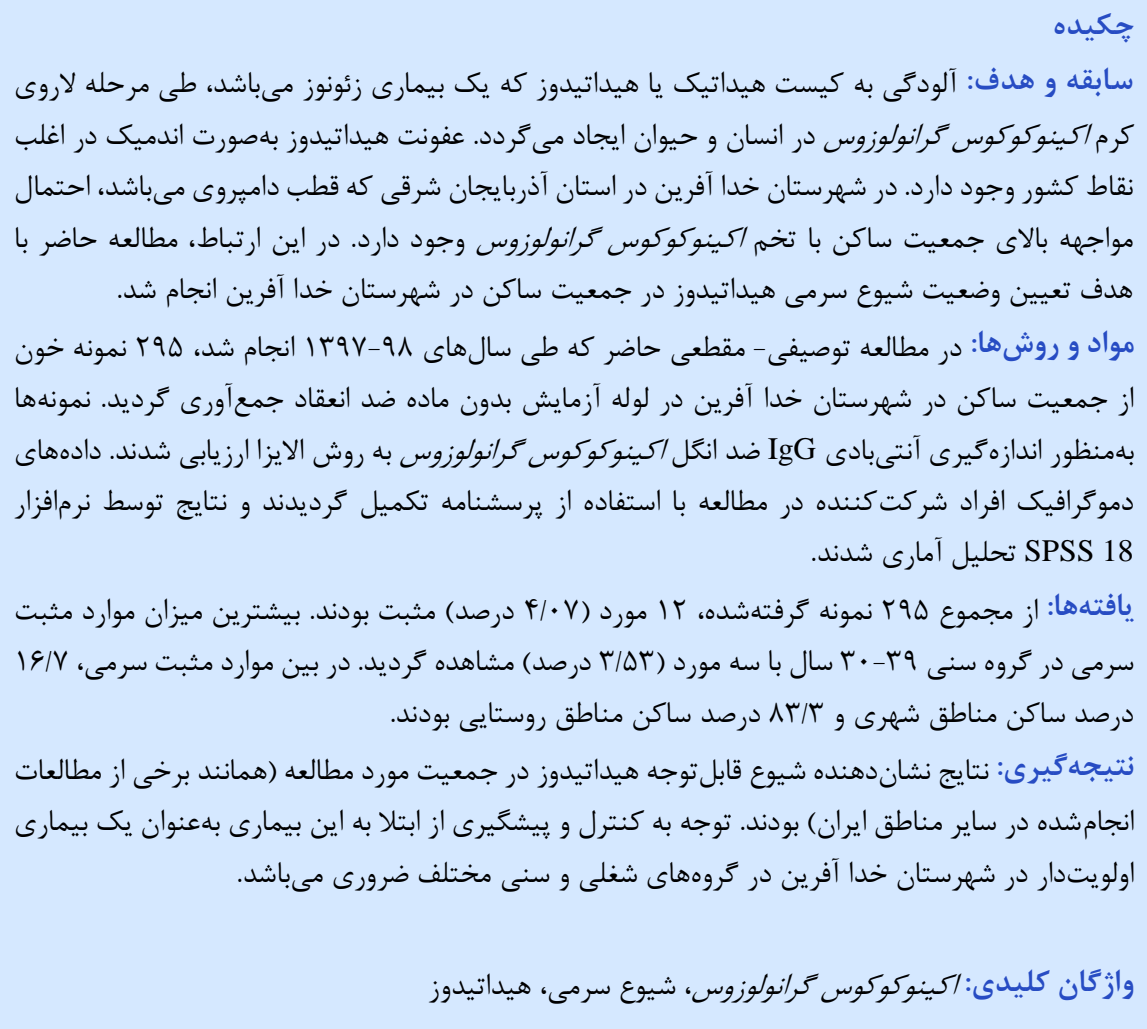 & 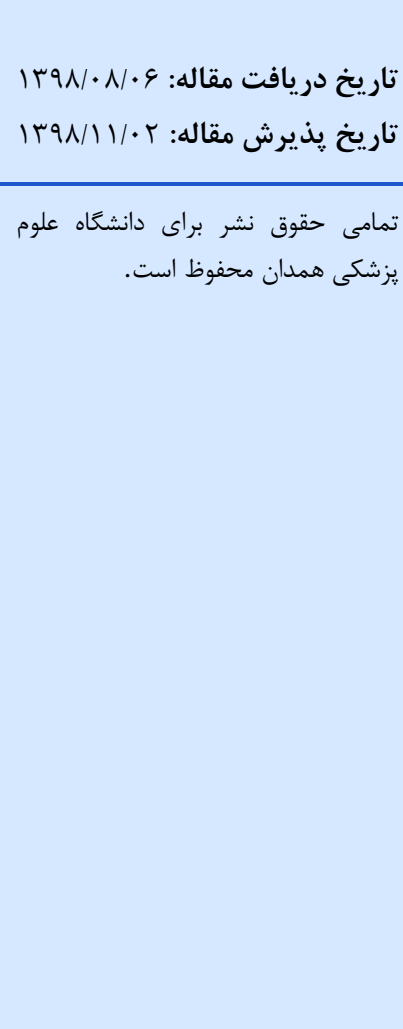 \\
\hline
\end{tabular}

و سبزيجات آلوده به تخم كرم است [ب]. آلودگى به اين انكل

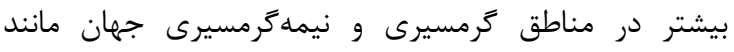
كشورهاى حوزه مديترانه، روسيه، خاورميانه، خاور دور، استر اليا،

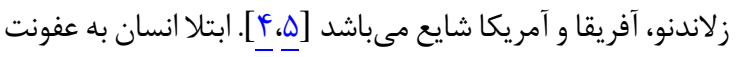

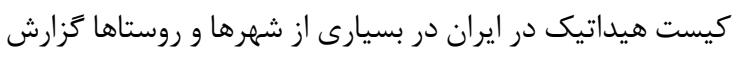

هيداتيدوز يك بيمارى انكلى مشترك بين انسان و دام با

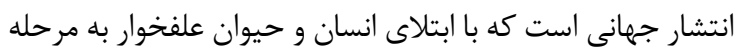

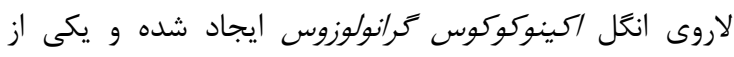

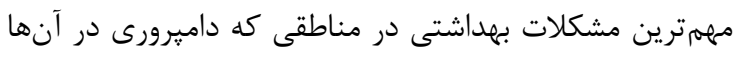

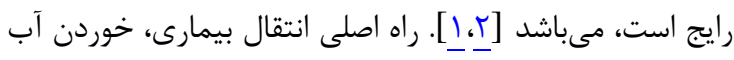


تعيين وضعيت شيوع سرمى هيداتيدوز در اين منطقه طراحى و

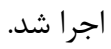

\section{مواد و روشىها}

مطالعه توصيفى - مقطعى حاضر در ارتباط با جمعيت ساكن در شهرستان خدا آفرين انجام شد. اين شهرستان از سمت دمت شمال

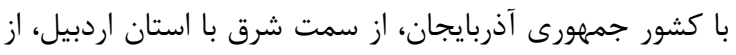

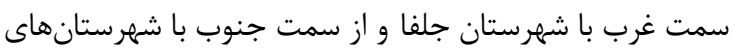
كليبر و ورزقان هممرز بوده و بهاعنوان دومين شهرستان

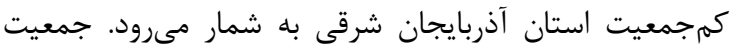

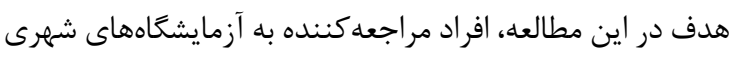
و شهرى- روستايى و هم:جنين مراكز نمونه كيرى مستقر در مراكز

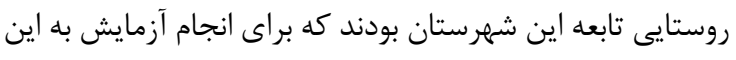

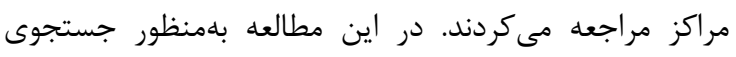

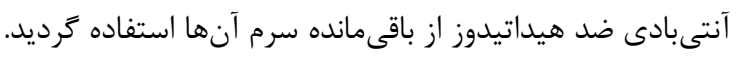

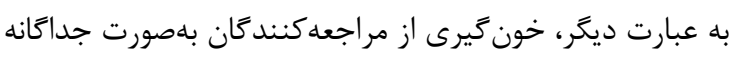

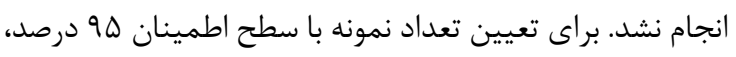

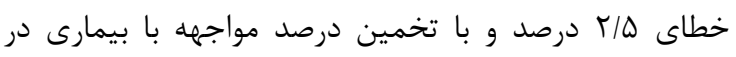

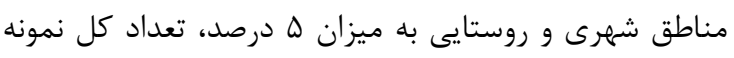

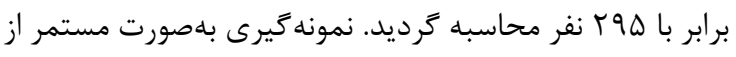

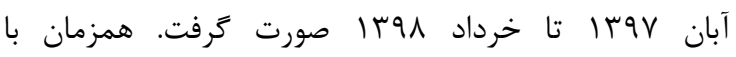

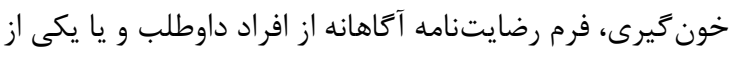

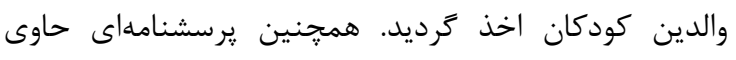
اطلاعات دموكرافيك از قبيل سن، جنس، محل سكونت، شغل،

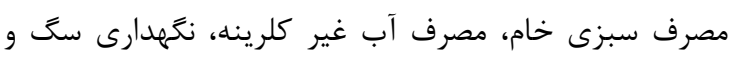

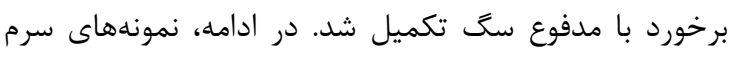

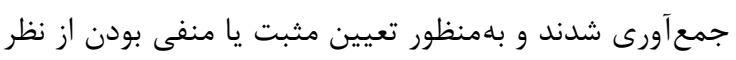

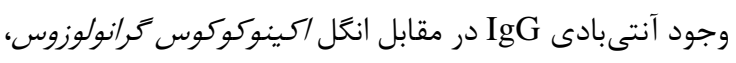

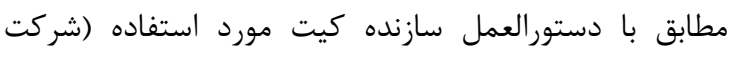
يمتاز طب، تهران، ايران) آزمايش شدند.

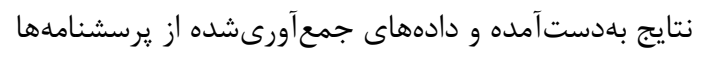

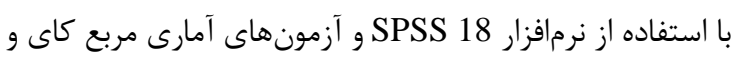
دقيق فيشر تحليل آمارى گرديدند.

\section{يافته ها}

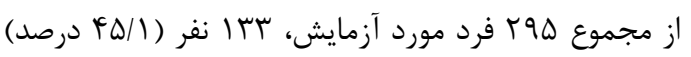

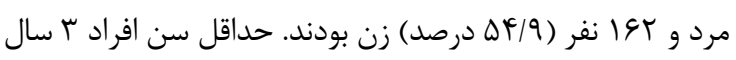

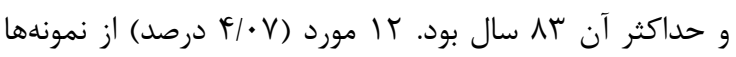

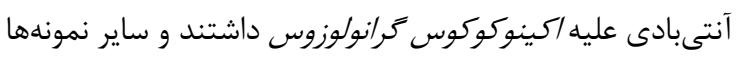

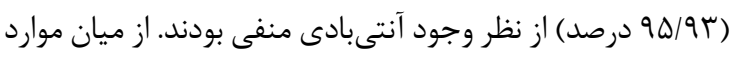

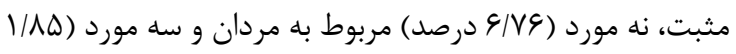

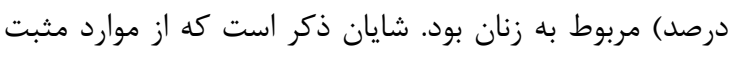

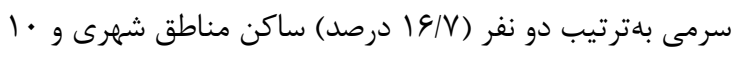

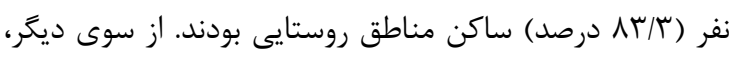

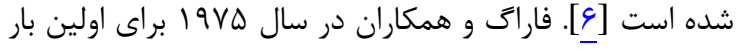
از آزمون الايزا (Enzyme-Linked Immunosorbent Assay)

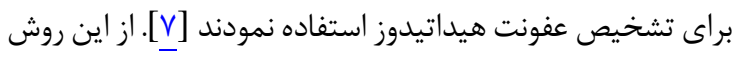

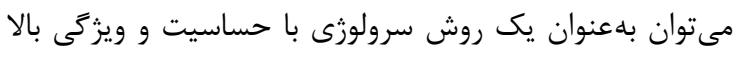

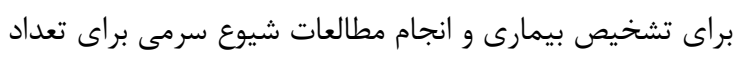

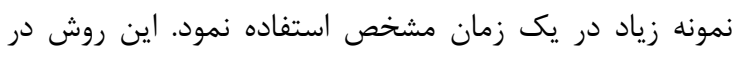

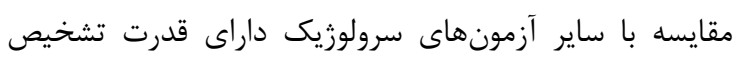

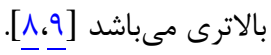

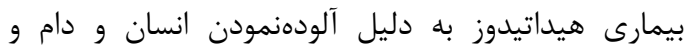
همجنين داشتن سويههاى مختلف، از نظر تشخيص و درمان

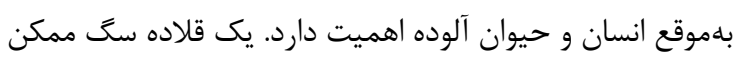

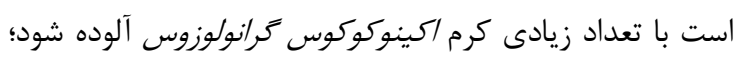

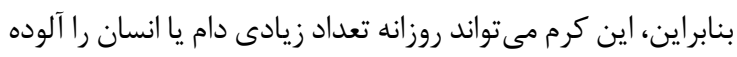

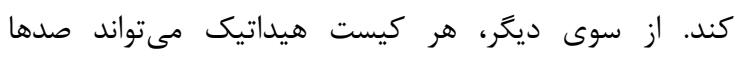

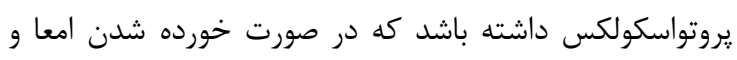

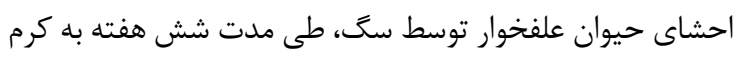

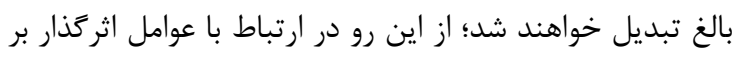

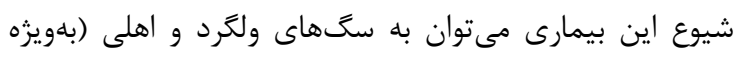

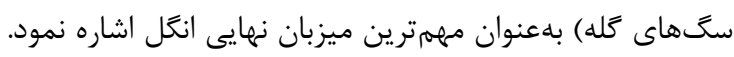

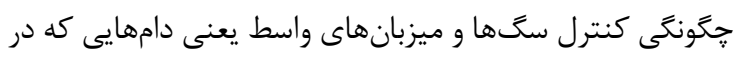
مناطق مختلف كشور بدون نظارت سازمان داميزشكى كشورى

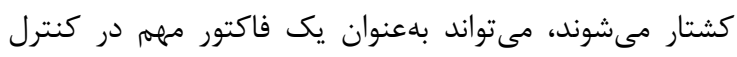

بيمارى مطرح باشد [ـ1].

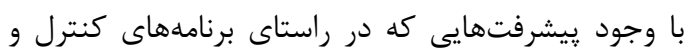

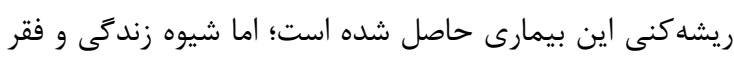

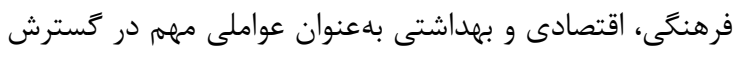

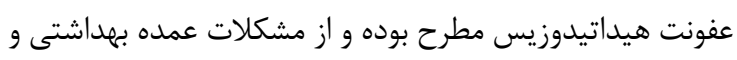

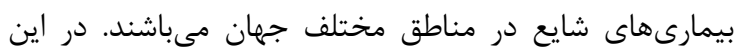

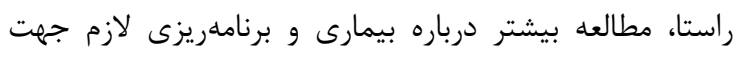

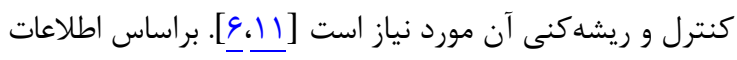

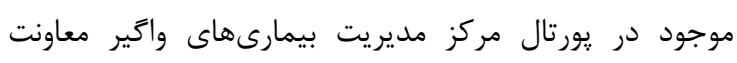

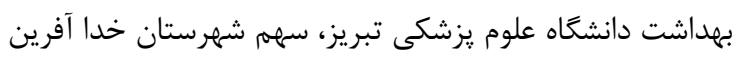

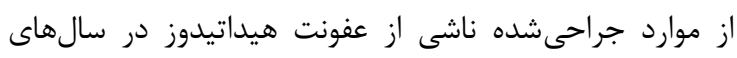

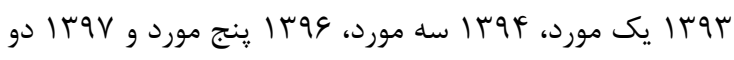
مورد بوده است. براساس دادههاى موجود، تعداد كل موارد

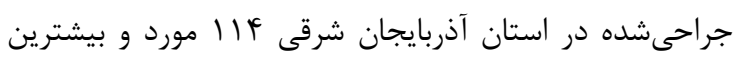

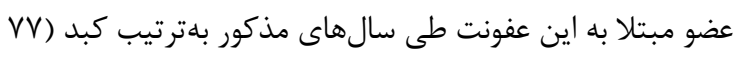

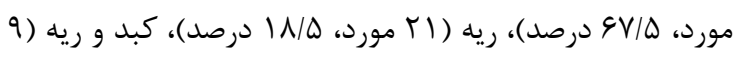

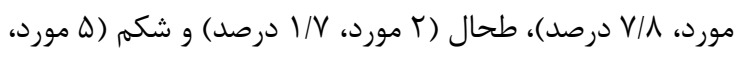

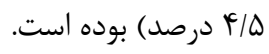

بر مبناى مطالب بيانشده، مطالعه حاضر با توجه به به كمبود

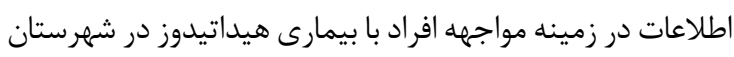

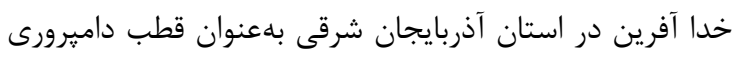

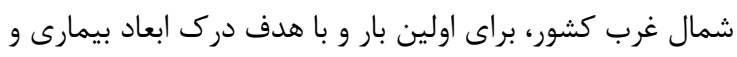


جدول ا: فراوانى وضعيت سرمى افراد شركت كننده در مطالعه بر حسب متغيرهاى جمعيتشناختى

\begin{tabular}{|c|c|c|c|c|c|}
\hline سطح معنادارى & تعد سرمى مجموع (درصد) & منفى تعداد & مثبت تعداد & & متغير \\
\hline$\cdot / r \cdot V$ & 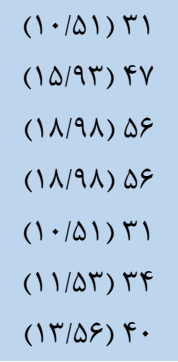 & 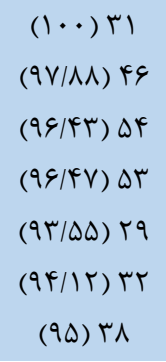 & 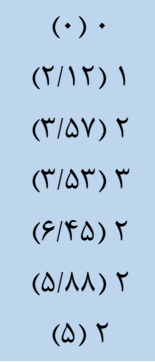 & $\begin{array}{r}1 \cdot-19 \\
r \cdot-r q \\
r \cdot-r q \\
r \cdot-r q \\
\Delta \cdot-\Delta q\end{array}$ & سن تقويمى \\
\hline س •|• & $\begin{array}{l}(F \Delta / \cdot \Lambda) \mid T r \\
(\Delta F / q T) \mid G T\end{array}$ & $\begin{array}{l}(q K / Y F) \backslash K F \\
(q / / Q \Delta) \backslash \Delta q\end{array}$ & $\begin{array}{l}(\varepsilon / \vee \varphi)^{q} \\
(1 / \wedge \Delta) r\end{array}$ & زرد & جنس \\
\hline $.1 \cdot 10$ & $\begin{array}{l}(\mid \Lambda / G Y) \Delta D \\
(G / I) \backslash \Lambda \\
(\cdot / G \Lambda) Y \\
(Y / \cdot Y) G \\
(Y / Y G) Y T \\
(Y / / \Delta T) q T \\
(Y Y / V \Delta) V Y \\
(\Lambda / A I) Y G\end{array}$ & 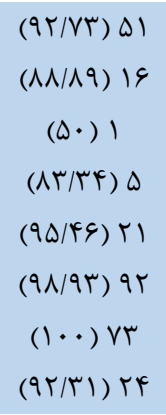 & 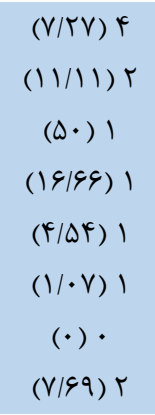 & كار كاردار & 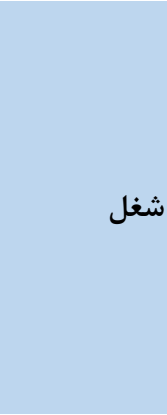 \\
\hline$\cdot 19 \cdot \Delta$ & $\begin{array}{l}(\Psi N / 9 \Delta) \| l F \\
(\Psi V / T q) \| l \\
(\mid V / q \Delta) \Delta r \\
(9 / 11)) 1 \Lambda\end{array}$ & 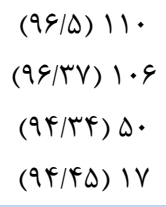 & $\begin{array}{l}(r / \Delta) Y \\
(r / Q \Psi) Y \\
(\Delta / \& Q) r \\
(\Delta / \Delta \Delta))\end{array}$ & دابتدايى & تحصيلات \\
\hline.$/ 189$ & 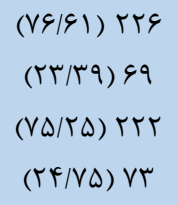 & $\begin{array}{l}(q F / V) Y I F \\
(1 \cdot \cdot) 9 q \\
(9 \Delta / \cdot \Delta) r I I \\
(9 \Lambda / q r) V T\end{array}$ & $\begin{array}{c}(\Delta / \Gamma) \mid r \\
(\cdot) \cdot \\
(\Psi / q \Delta) \backslash \mid \\
(\mid / r V) \mid\end{array}$ & سبز آب سبجات آب تصفيهن خام دارد ندارد & سابقه مصرف \\
\hline .1119 & 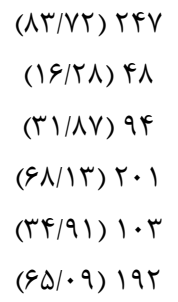 & 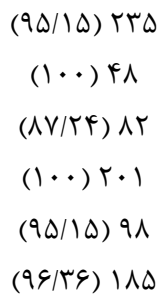 & $\begin{array}{c}(\Psi / \wedge \Delta) \mid r \\
(\cdot) \cdot \\
(\mid r / V G) \mid r \\
(\cdot) \cdot \\
(Y / \wedge \Delta) \Delta \\
(r / Q Y) V\end{array}$ & 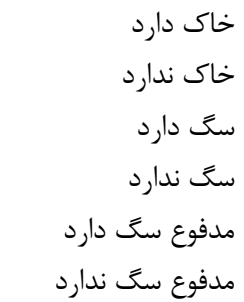 & سابقه تماس \\
\hline
\end{tabular}

مناطق روستايى نسبت به مناطق شهرى بالاتر بود كه اين اختلاف

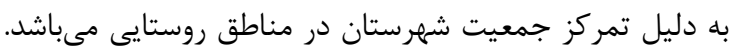

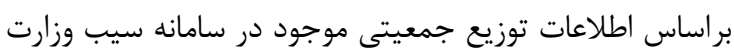

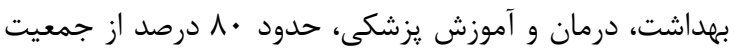

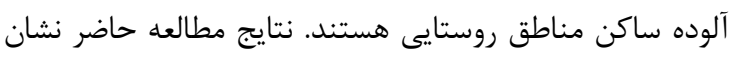

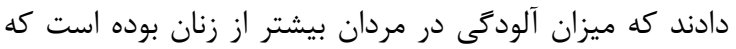

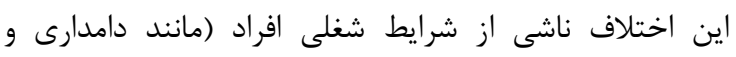

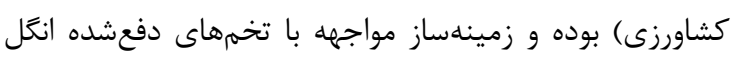

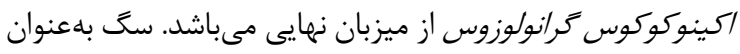

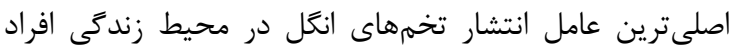

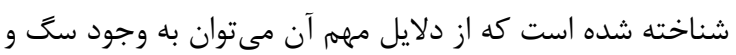

بيشتر افراد سرم مثبت در گروههايى قرار داشتند كه سابقه تماس

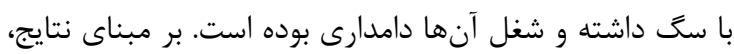

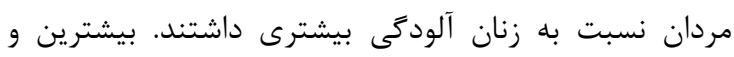

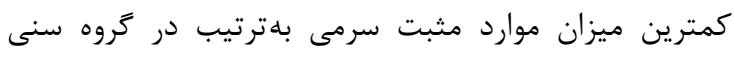

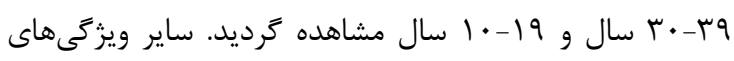
جمعيتشناختى افراد مورد مطالعه در جدول ا ارائه شده است.

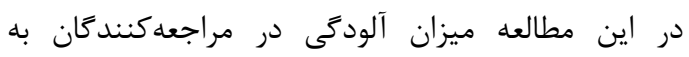

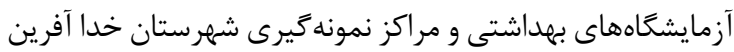

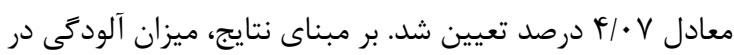


معنادارى بين سطح تحصيلات افراد سرم مثبت مشاهده نگرديد

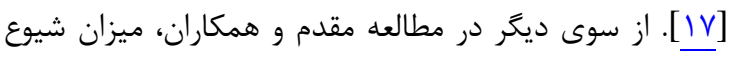

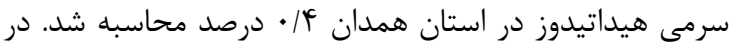

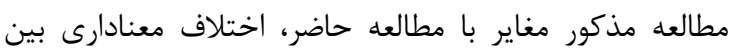

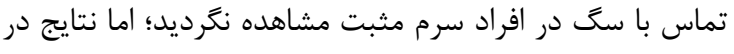

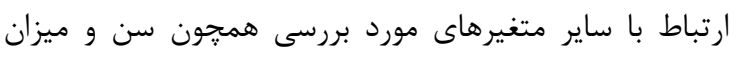

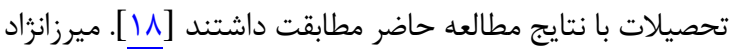

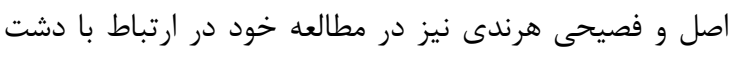

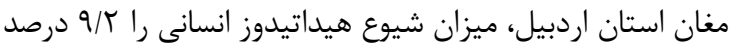

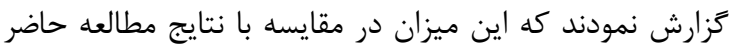

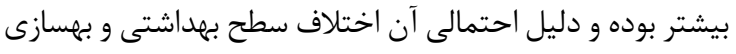

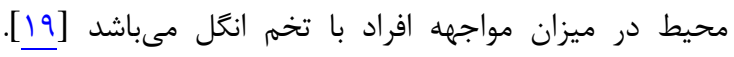
علاوهبراين، اصغرى و همكاران مطالعهاى را در شهر اراك مواى انجام

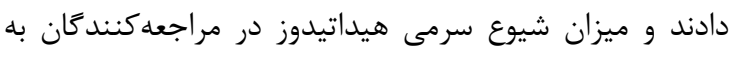

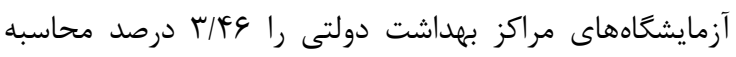

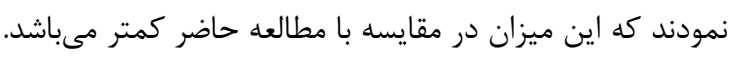

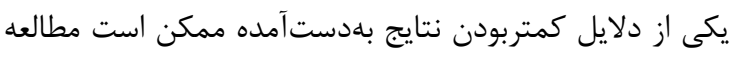

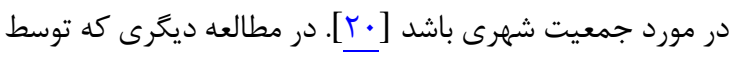

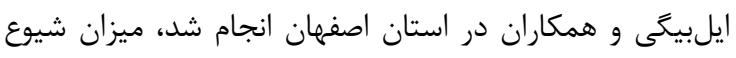

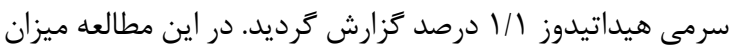

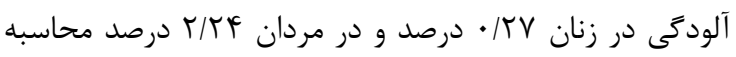
شد كه مطابق با مطالعه حاضر، اين اختلاف از نظر آمارى معنادار

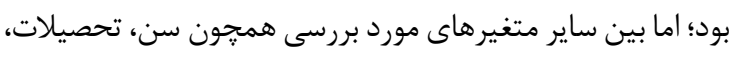

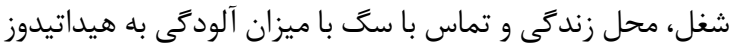

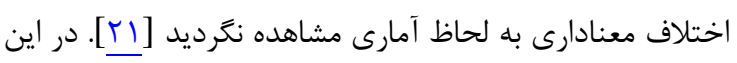

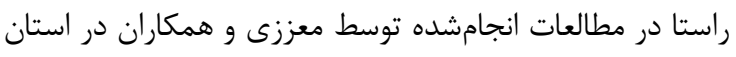

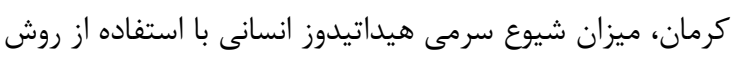

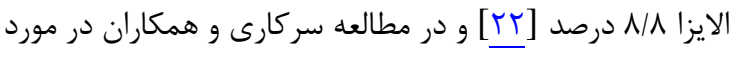

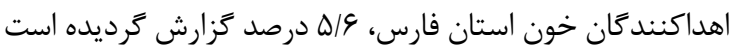
[rr] كه با نتايج مطالعه حاضر همخوانى دارند. در مطالعات صورت

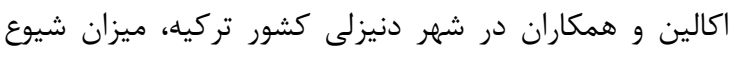

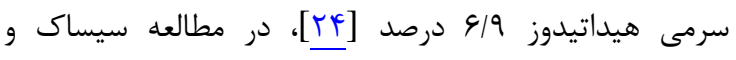
همكاران در روستاهاى كشور هلند

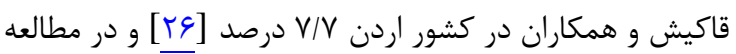

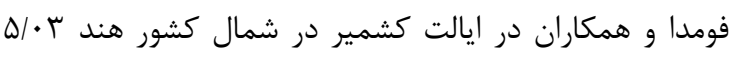
درصد گزارش شده است [rV] يافتههاى مطالعه حاضر ندارند. در مطالعه حاضر و مطالعات مذكور، ميزان موارد مثبت ماضت نداند

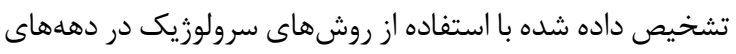

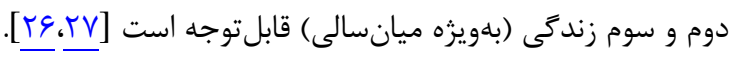

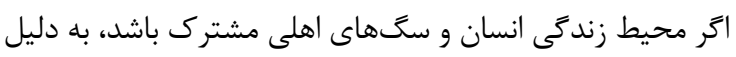

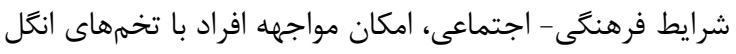

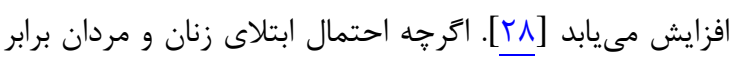

همزيستى اين حيوان با انسان به واسطه شغل دامدارى و نيز

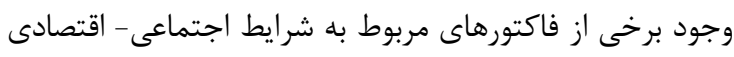

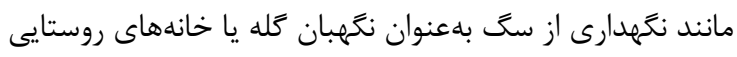

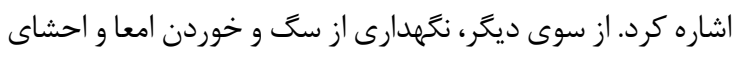

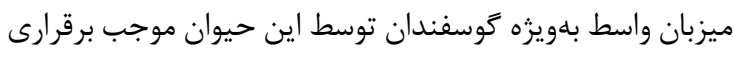

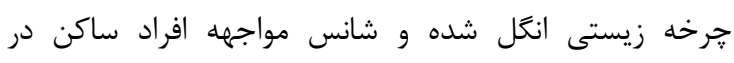

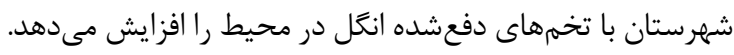

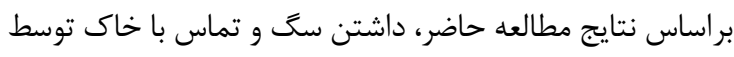

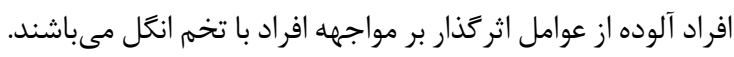

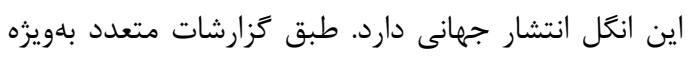

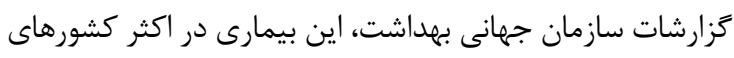

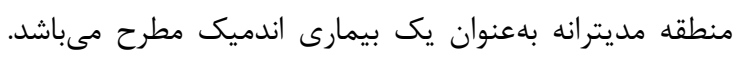

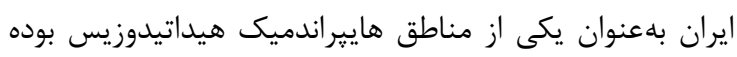

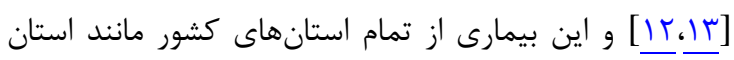

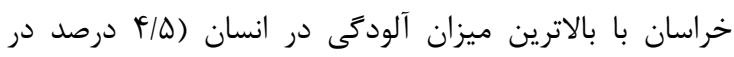

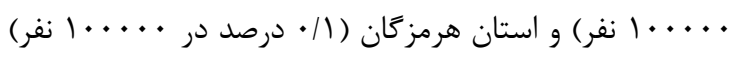

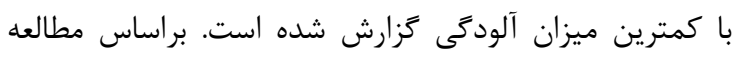

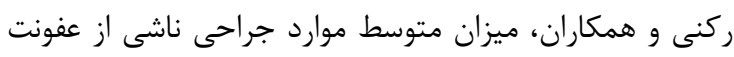

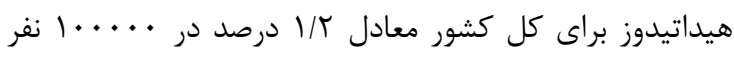
مىباشد [ع]. بيمارى هيداتيدوز به ديد دليل نداشتن علائم و

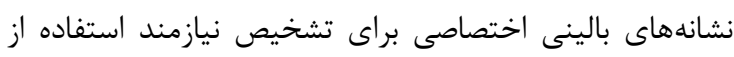

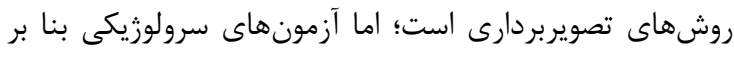

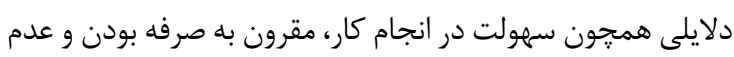

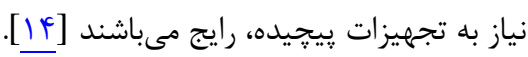

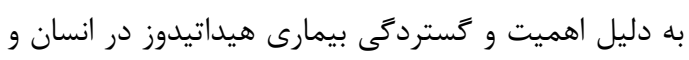

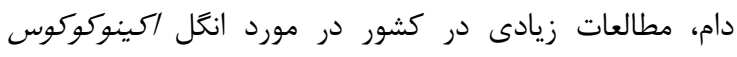

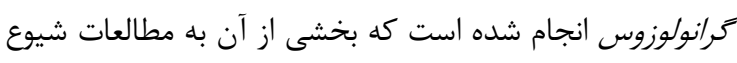
سرمى آلودكى به مرحله لاروى (كيست هيداتيك) در انسان

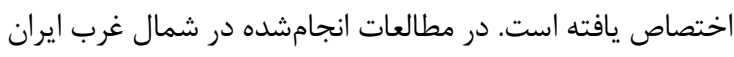

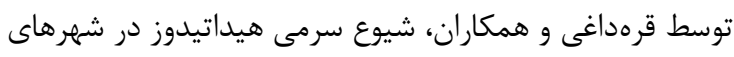

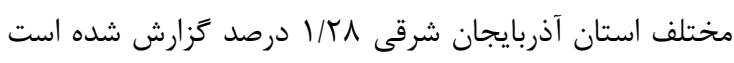

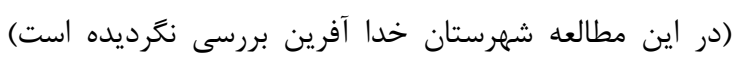

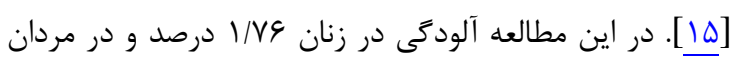

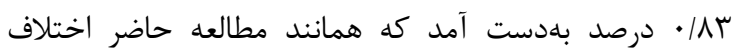

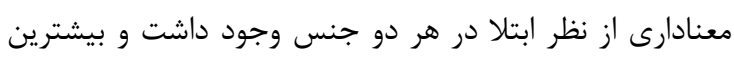

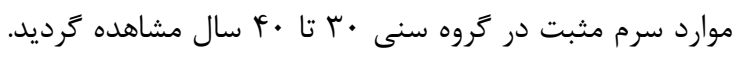

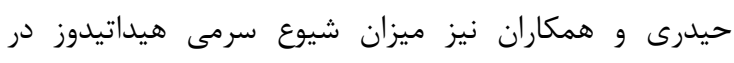

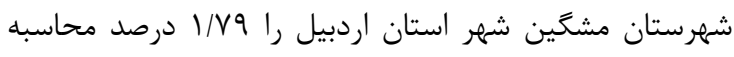

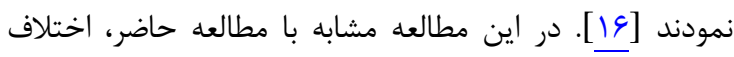

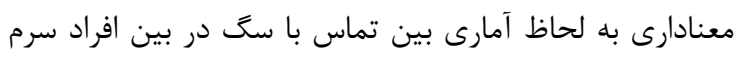
مثبت مشاهده شد.

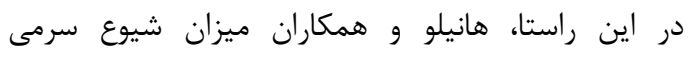

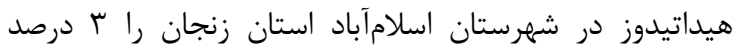
كزارش نمودند. در اين مطالعه همانند مطالعه حاضر اختلاف 


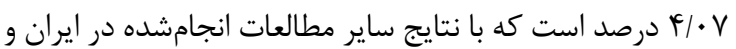
ساير كشورها مطابقت دارد و نشاندهنده انتشار جهانى اين

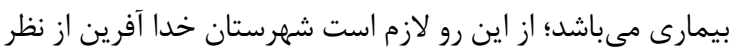
وجود اين عفونت بيشتر مورد توجه قرار گيرد.

\section{تشكر و قلر داذى}

اين مقاله بركرفته از طرح تحقيقاتى مصوب دانشگاه علوم

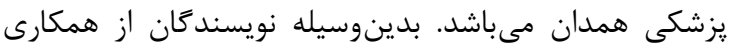

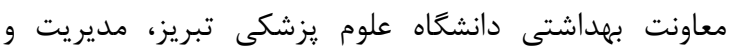

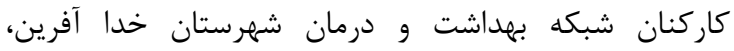

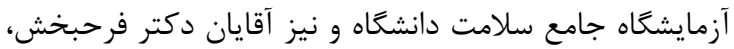

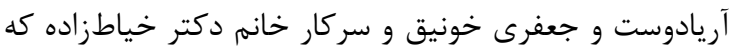
در تجزيه و تحليل آمارى اين طرح مشاركت نمودند، تشكر و ودئ قدردانى مى نمايند.

\section{تضاد منافع}

هيج كونه تعارض منافعى بين نويسندًان و نتايج مطالعه

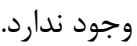

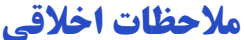

اين مطالعه يس از اخذ تأييديه از كميته اخلاق در يزوهش

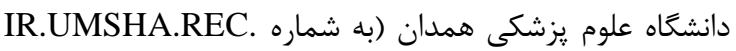

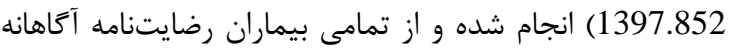

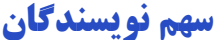

نويسنده اول (يزووهشخر اصلى): تدوين نتايج، تفسير دادهها،

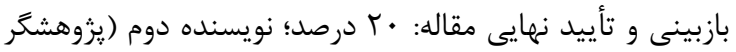
اصلى): تدوين مقدمه، مشاركت در آناليز دادهها و ويرايش مقاله: • 1 درصد؛ نويسنده سوم (يزوهشكر همكار): مشاركت در در آناليز دادها و نكارش پيشنويس مقاله: · ل درصد؛ نويسنده جهارم

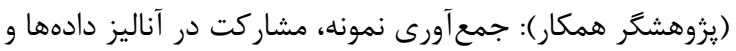

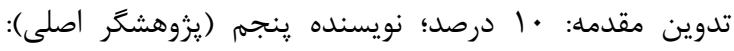

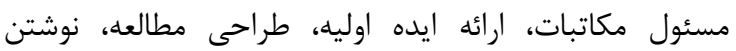

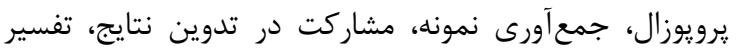

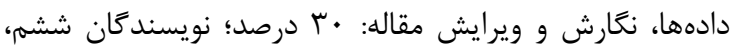

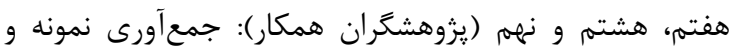

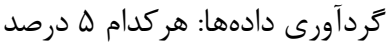

\section{حمايت مالَى}

اين طرح تحقيقاتى از سوى مركز يروهش دانشجويان دانشخاه علوم يزشكى همدان تأمين مالى شده است.
بوده و بيمارى از نظر آلودهردن افراد ارتباطى با جنس ندارد؛ اما

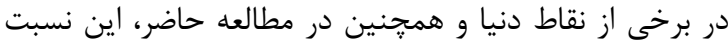

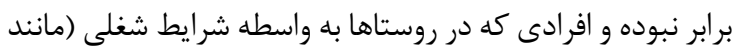

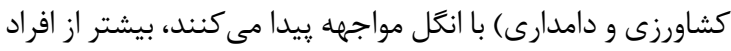
عادى مىباشند [بr]. با توجه به شيوع سرمى قابلتوجه هيداتيدوز در شهرستان

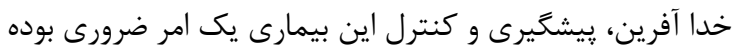

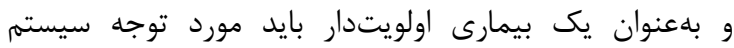

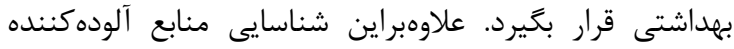

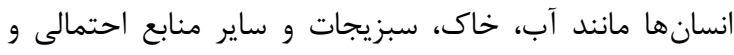

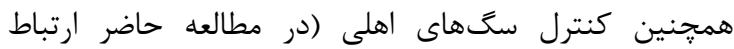

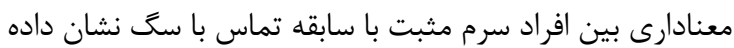

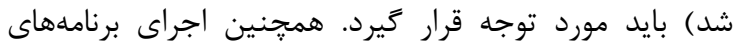

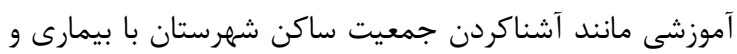

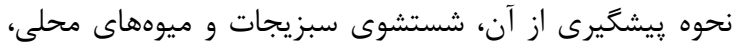

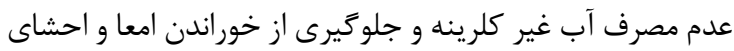

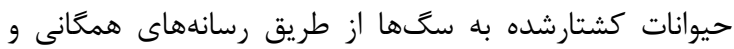

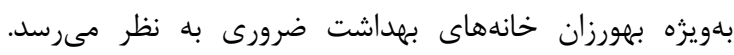

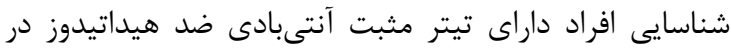

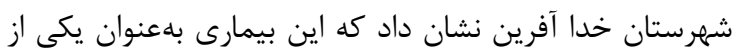

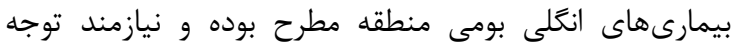

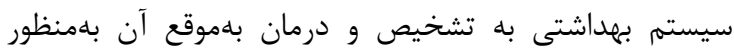

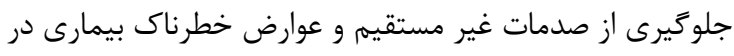

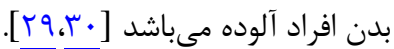
مثبتبودن افراد با روشهاى سرولوزيك دليلى بردي بر ابتلاى

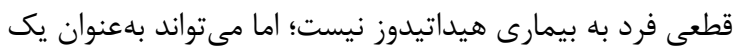
روش غربالكرى جهت شناسايى افراد درگير بيمارى و انجام روشهاى تصويربردارى تكميلى مورد استفاده قرار بكيرديرد روش هاى سرولوزيك و تعيين شيوع سرمى بيمارى هيداتيدوز در

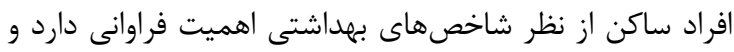

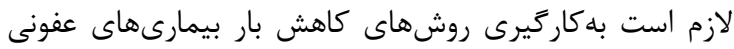

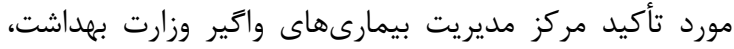

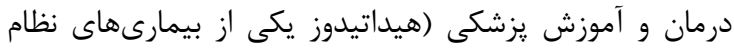

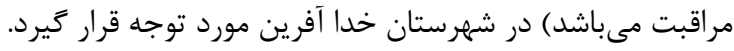
بلمنظور تعيين قطعى وجود عفونت فعال هيداتيدوز در افراد سرم دئن

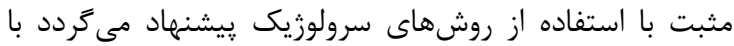
بهره گيرى از روشهاى تكميلى مانند سونوكرافى، مطالعات

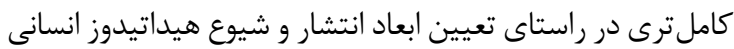
در سطح شهرستان انجام شود.

نتيجه كيرى

براساس يافتهاى مطالعه حاضر، شيوع سرمى هيداتيدوز 


\section{REFERENCES}

1. Moro PL, Garcia HH, Gonzales AE, Bonilla JJ, Verastegui M, GilmanMD RH. Screening for cystic echinococcosis in an endemic region of Peru using portable ultrasonography and the enzyme-linked immunoelectrotransfer blot (EITB) assay. Parasitol Res. 2005;96(4):242-6. PMID: 15875215 DOI: 10.1007/s00436-005-1350-6

2. Torgerson PR, Devleesschauwer B, Praet N, Speybroeck N, Willingham AL, Kasuga F, et al. World Health Organization estimates of the global and regional disease burden of 11 foodborne parasitic diseases, 2010: a data synthesis. PLoS Med. 2015;12(12):e1001920. PMID: 26633705 DOI: 10.1371/journal.pmed.1001920

3. Craig PS, McManus DP, Lightowlers MW, Chabalgoity JA, Garcia HH, Gavidia CM, et al. Prevention and control of cystic echinococcosis. Lancet Infect Dis. 2007;7(6):385-94. PMID: 17521591 DOI: 10.1016/S1473-3099(07)70134-2

4. Eslami A, Hosseini SH. Echinococcusgranulosus infection of farm dogs of Iran. Parasitol Res. 1998;84(3):205-7. PMID: 9521009 DOI: $10.1007 / \mathrm{s} 004360050383$

5. Mobedi I. Dalimi Asl A. Epidemiology of hydatic cyst in the world and Iran. Tehran: Mogadam Press; 1994.

6. Rokni MB. Echinococcosis/hydatidosis in Iran. Iran $J$ Parasitol. 2009;4(2):1-16. DOI: 10.1016/s1201-9712(09) 60564-6

7. Farag H, Bout D, Capron A. Specific immunodiagnosis of human hydatidosis by the enzyme linked immunosorbent assay (ELISA). Biomedicine. 1975;23(7):276-8. PMID: 782577

8. Sbihi Y, Rmiqui A, Rodriguez-Cabezas MN, Orduña A, Rodriguez-Torres A, Osuna A. Comparative sensitivity of six serological tests and diagnostic value of ELISA using purified antigen in hydatidosis. $J$ Clin Lab Analys. 2001;15(1):14-8. PMID: 11170228 DOI: 10.1002/10982825(2001)15:1<14::aid-jcla3>3.0.co;2-7

9. Mamuti W, Yamasaki H, Sako Y, Nakao M, Xiao N, Nakaya $\mathrm{K}$, et al. Molecular cloning, expression, and serological evaluation of an 8-kilodalton subunit of antigen B from Echinococcus multilocularis. J Clin Microbiol. 2004; 42(3):1082-8. PMID: 15004057 DOI: $10.1128 / \mathrm{jcm} .42 .3 .1082-$ 1088.2004

10. Thompson R, McManus D. Aetiology: parasites and lifecycles. World Organ Animal Health. 2001;12:1-19.

11. Barnes AN, Davaasuren A, Baasandagva U, Gray GC. A systematic review of zoonotic enteric parasitic diseases among nomadic and pastoral people. PloS One. 2017; 12(11):e0188809. PMID: 29190664 DOI: 10.1371/journal. pone.0188809

12. Mousavi S, Samsami M, Fallah M, Zirakzadeh H. A retrospective survey of human hydatidosis based on hospital records during the period of 10 years. J Parasitic Diss. 2012;36(1):7-9. PMID: 23542872 DOI: 10.1007/s12639011-0093-9

13. Dakkak A. Echinococcosis/hydatidosis: a severe threat in Mediterranean countries. Veter Parasitol. 2010;174(1-2):211. PMID: 20888694 DOI: 10.1016/j.vetpar.2010.08.009

14. Babba H, Messedi A, Masmoudi S, Zribi M, Grillot R, Ambriose-Thomas P, et al. Diagnosis of human hydatidosis: comparison between imagery and six serologic techniques. Am J Trop Med Hyg. 1994;50(1):64-8. PMID: 8304574 DOI: 10.4269/ajtmh.1994.50.64

15. Garedaghi Y, Bahavarnia SR. Seroepidemiological study of hydatid cyst by ELISAmethod in East-Azarbaijan Province. J Kerman Univ Med Sci. 2015;18(2):181-72. [Persian]

16. Heidari Z, Mohebali M, Zarei Z, Aryayipour M ,Eshraghian M, Kia E, et al. Seroepidemiological study of human hydatidosis in Meshkinshahr district, Ardabil province, Iran. Iran J Parasitol. 2011;6(3):19. PMID: 22347293

17. Hanilou A, Badali H, Esmaeilzadeh A. Seroepidemiological study of hydatidosis in Zanjan (Islam-Abad 2002). J Adv Med Biomed Res. 2004;12(46):41-6. [Persian]

18. Moghadam MB, Hajilooi M, Fallah M, Maghsood AH, Matini M. Seroprevalence of Hydatidosis in Outpatients Attending Health Centers in Hamadan City, 2017. Avicenna J Clin Med. 2018;25(2):99-104. DOI: 10.21859/ajcm.25.2.99

19. Mirzanezhad-Asl H, Fasihi Harandi M. Seroepidemiological survey of human cystic echinococcosis with ELISA method in Moghan plain, Ardabil province. J Ardabil Univ Med Sci. 2009;9(4):334-46.

20. Asghari M, Mohebali M, Kia EB, Farahnak A, Aryaeipour M, Asadian S, et al. Seroepidemiology of human hydatidosis using AgB-ELISA test in Arak, central Iran. Iran J Public Health. 2013;42(4):391-6. PMID: 23785678

21. Ilbeigi P, Mohebali M, Kia EB, Saber-Inasab M, Aryaeipour M, Bizhani N, et al. Seroepidemiology of human hydatidosis using AgB-ELISA test in Isfahan city and suburb Areas, Isfahan Province, central Iran. Iran $J$ Public Health. 2015;44(9):1219.-24. PMID: 26587496

22. Moazezi SS, Fasihi Harandi M, Saba M, Kamyabi H. Sonographic and serological survey of hydatid disease in rural regions of Shahdad and Chatroud, Kerman province, 2006-2007. J Kerman Univ Med Scis. 2015;16(1):25-34.

23. Sarkari B, Hosseini F, Abdolahi Khabisi S, Sedaghat F. Seroprevalence of cystic echinococcosis in blood donors in Fars province, southern Iran. Parasite Epidemiol Control. 2017;2(1):8-12. PMID: 29774277 DOI: 10.1016/j.parepi. 2016.12.002

24. Akalin S, Kutlu SS, Caylak SD, Onal O, Kaya S, Bozkurt Aİ. Seroprevalence of human cystic echinococcosis and risk factors in animal breeders in rural communities in Denizli, Turkey. J Infect Develop Ctries. 2014;8(9):1188-94. PMID: 25212084 DOI: 10.3855 /jidc.4343

25. Cisak E, Sroka J, Wójcik-Fatla A, Zając V, Dutkiewicz J. Evaluation of reactivity to Echinococcus spp. among rural inhabitants in Poland. Acta Parasitol. 2015;60(3):525-9. PMID: 26204192 DOI: 10.1515/ap-2015-0074

26. Qaqish A, Nasrieh M, Al-Qaoud K, Craig P, Abdel-Hafez S. The seroprevalences of cystic echinococcosis, and the associated risk factors, in rural-agricultural, bedouin and semi-bedouin communities in Jordan. Ann Trop Med Parasitol. 2003;97(5):511-20. PMID: 12930615 DOI: 10.1179/000349803225001436

27. Fomda BA, KhanA, Thokar MA, Malik AA, Fazili A, Dar RA, et al. Sero-epidemiological survey of human cystic echinococcosis in Kashmir, North India. PLoS One. 2015;10(4):e0124813. PMID: 25915867 DOI: 10.1371/ journal.pone.0124813

28. Rafiei A, Hemadi A, Maraghi S, Kaikhaei B, Craig PS. Human cystic echinococcosis in nomads of south-west Islamic Republic of Iran. East Mediterr Health J. 2007;13(1):41-8. PMID: 17546904

29. Ghabouli Mehrabani N, Kousha A, Khalili M, Oskouei MM, Mohammadzadeh M, Alizadeh S, et al. Hydatid cyst surgeries in patients referred to hospitals in East Azerbaijan province during 2009-2011. Iran J Parasitol. 2014;9(2):233. PMID: 25848390

30. Siracusano A, Delunardo F, Teggi A, Ortona E. Cystic echinococcosis: aspects of immune response, immunopathogenesis and immune evasion from the human host. Endocr Metab Immune Disord Drug Targets. 2012;12(1):1623. PMID: 22214328 DOI: $10.2174 / 187153012799279117$ 